\title{
EDITORIAL
}

\section{Multivariate analysis of hyperglycemia in extremely low birth weight infants}

\author{
Journal of Perinatology (2006) 26, 723-725. doi:10.1038/sj.jp.7211614
}

Extremely low birth weight (ELBW) infants comprise a large subset of the neonatal intensive care unit (ICU) population. They have impaired glucose tolerance attributed to insufficient processing of pro-insulin by the immature pancreas, and decreased sensitivity of the liver to insulin, leading to continuous glucose production despite hyperglycemia. ${ }^{1,2}$ The relationship between hyperglycemia and morbidity (e.g., intraventricular hemorrhage, which could be mediated by changes in osmolal concentration) ${ }^{3}$ and mortality in this population is still not clearly defined. In this month's Journal of Perinatology, Kao et al. ${ }^{4}$ and Blanco et al..$^{5}$ describe multivariate analyses of this relationship in large samples of ELBW infants from single-site centers.

There is no consensus about the exact definition of neonatal hyperglycemia. Several authors have used statistical definitions, for example, blood glucose concentration greater than $7 \mathrm{~mm} / \mathrm{l}$ $(126 \mathrm{mg} / \mathrm{dl})$; Hey ${ }^{6}$ used operational targets, for example, level of glycemia leading to osmotic diuresis associated with glucosuria. The latter definition is limited by poor concordance between hyperglycemia and glucosuria in preterm infants. ${ }^{7}$ Lack of consensus has made comparison of different studies difficult.

Hyperglycemia in the neonatal period may result from high exogenous glucose intake, stress (sepsis, necrotizing enterocolitis, intracerebral event and immediate postoperative phase) or medications (high-dose postnatal steroids and theophylline). ${ }^{6}$ In a case-control study involving 47 very low birth weight (VLBW) infants Garg et al. ${ }^{8}$ showed an association between increasing mean blood glucose levels and severe retinopathy of prematurity (ROP), using logistic regression analysis and multiple regression analysis. Ertl et al. ${ }^{9}$ found a significant relationship between hyperglycemia and ROP in 201 VLBW infants using logistic regression analysis; however, this relationship did not reach statistical significance in the subset of 63 ELBW infants.

In adults and children, hyperglycemia is a risk factor of mortality for patients with various medical or surgical conditions. ${ }^{10-12}$ In two large randomized trials, respectively in a surgical and in a medical ICU, Van Den Berghe et al. ${ }^{13,14}$ showed that intensive continuous insulin infusion to limit glucose concentration below $110 \mathrm{mg} / \mathrm{dl}(6.1 \mathrm{~mm} / \mathrm{l})$ versus below $215 \mathrm{mg} / \mathrm{dl}$ $(12 \mathrm{~mm} / \mathrm{l})$ reduced morbidity; it also reduced mortality in the surgical ICU trial. A laboratory study manipulating insulin and glucose independently showed that the observed benefits of intensive insulin therapy required maintenance of normoglycemia. ${ }^{15}$

Both studies in this issue of Journal of Perinatology ${ }^{4,5}$ found a strong association between hyperglycemia and low gestational age, whereas the association between hyperglycemia and low birth weight was either less strong ${ }^{4}$ or not significant. ${ }^{5}$ Kao et al. ${ }^{4}$ found a significant association between their primary outcome variable, that is, a composite outcome of either mortality or late-onset culture-proven infection (odds ratio (OR) 5.07, 95\% confidence interval (CI) 1.06 to 24.3) and early (the first 3 days) severe hyperglycemia (defined as mean morning glucose equal to or greater than $180 \mathrm{mg} / \mathrm{dl}$ ) after adjusting for gestational age. They also found an association of hyperglycemia (both severe early and persistent) with NEC stage II/III (OR 9.49, 95\% CI 1.52 to 59.3) after adjusting for age and male gender, and an association of mortality with early (OR 15.7, 95\% CI 3.74 to 65.9) or persistent (OR 30.4, 95\% CI 3.37 to 274) severe hyperglycemia. Kao et al. ${ }^{4}$ found no significant association of hyperglycemia with total number of days of mechanical ventilation among survivors and length of stay for survivors not transferred to another facility. Blanco et al. ${ }^{5}$ after adjusting for gestational age, birth weight, postnatal steroids and sepsis, showed an inverse association between hyperglycemia and chorioamnionitis (OR 0.10, 95\% CI $0.01-0.64)$. Blanco et al..$^{5}$ also found an association between hyperglycemia and ROP (OR 4.6, 95\% CI 1.1-8.9). There was no association between hyperglycemia and birth weight, sepsis, death, prolonged hospital stay, bronchopulmonary dysplasia, intraventricular hemorrhage or postnatal steroid exposure. Lack of association of hyperglycemia with postnatal steroid exposure most likely results from the current trend in reducing the doses of postnatal steroids in preterm infants. As these two studies used different populations, different definitions of hyperglycemia, different variables and different strategies to combine variables in their analyses, it is not surprising that they reached different conclusions. Although the authors wisely selected a strategy designed to limit the number of variables, the relatively small sample size could have limited the power of detecting small differences in specific variables.

The retrospective nature of both studies only allowed the authors to test associations. These studies raise additional hypotheses, but do not demonstrate causality. Kao et al. ${ }^{4}$ analyzed 
outcomes of mortality and infection based on the degree of hyperglycemia and its duration in ELBW infants. Blanco et al. ${ }^{5}$ analyzed factors that could be conceived as causal for hyperglycemia separate from those that could be conceived as secondary to hyperglycemia. Whether the association of hyperglycemia with mortality or sepsis and whether the association of hyperglycemia with ROP is causal remain to be assessed by a randomized trial. As tight glucose control is crucial in limiting serum levels of vascular endothelial growth factor (VEGF) ${ }^{16}$ and progression of diabetic retinopathy, ${ }^{17}$ it is plausible that hyperglycemia might contribute to ROP. However, acute intensive insulin therapy may exacerbate diabetic retinopathy by increasing blood-retinal barrier breakdown via hypoxia-inducible factor 1- $\alpha$ and VEGF. ${ }^{18}$

Future researchers may use the information from these two studies in this issue of Journal of Perinatology, especially factors reaching significance, for designing a multicenter observational or randomized trial. A randomized trial would be needed to assess whether treatment of hyperglycemia may affect short-term outcomes in the most immature infants as well as long-term growth, ROP and neurodevelopmental outcome. So far, only a single small randomized trial ${ }^{19}$ has assessed the effects of insulin therapy on neonatal hyperglycemia. In this study, ELBW infants with hyperglycemia defined as a single blood sugar concentration $>240 \mathrm{mg} / \mathrm{dl}$ or repeated blood sugars $>160 \mathrm{mg} / \mathrm{dl}$ for at least $4 \mathrm{~h}$ were randomized to insulin versus glucose reduction. The 12 patients randomized to insulin received more calories than the 11 receiving reduced glucose intake and received a caloric intake $<60 \mathrm{kcal} / \mathrm{kg} /$ day for $8.6 \pm 1.3$ days, compared with $5.5 \pm 0.6$ days in controls. Several nutritional studies have shown the benefit of early postnatal nutrition, including enough glucose intake to meet glucose needs, ${ }^{20}$ on long-term growth. Insulin infusion has been used safely, allowing hyperglycemic infants to achieve adequate caloric intake similar to euglycemic infants. ${ }^{21}$ Therefore, limiting glucose intake below standard dose of 4 to $7 \mathrm{mg} / \mathrm{kg} / \mathrm{min}$ is not recommended. The current literature supports the initiation of a randomized controlled trial in extremely preterm infants with mild-to-moderate hyperglycemia assessing the effects of insulin infusion on important outcomes, including those assessed in Kao's and Blanco's studies.

LM Soghier $^{1}$ and LP Brion ${ }^{2}$ ${ }^{1}$ Children's Hospital of Philadelphia, Department of Pediatrics, Philadelphia, PA, USA and ${ }^{2}$ Children's Hospital at Montefiore, Department of Pediatrics, Bronx, NY, USA E-mail:lbrion@montefiore.org

\section{References}

1 Mitanchez-Mokhtari D, Lahlou N, Kieffer F, Magny JF, Roger M, Voyer M. Both relative insulin resistance and defective islet beta-cell processing of proinsulin are responsible for transient hyperglycemia in extremely preterm infants. Pediatrics 2004; 113: 537-541.

2 Farrag HM, Nawrath LM, Healey JE, Dorcus EJ, Rapoza RE, Oh W et al. Persistent glucose production and greater peripheral sensitivity to insulin in the neonate vs the adult. Am J Physiol Endocrinol Metab 1997; 272: E86-E93.

3 Finberg L, Finber L. Dangers to infants caused by changes in osmolal concentration. Pediatrics 1967; 40: 1031-1034.

4 Kao LS, Morris BH, Lally KP, Stewart CD, Huseby V, Kennedy KA. Hyperglycemia and morbidity and mortality in extremely low birth weight infants. J Perinatol 2006; doi:10.1038/sj.jp.7211593 (E-pub ahead of print).

5 Blanco CL, Baillargeon JG, Morrison RL, Gong AK. Hyperglycemia in extremely low birth weight infants in a predominantly Hispanic population and related morbidities. J Perinatol 2006; doi:10.1038/sj.jp.7211594 (E-pub ahead of print).

6 Hey E. Hyperglycaemia and the very preterm baby. Semin Fetal Neonatal Med 2005; 10: 377-387.

7 Falcao MC, Ramos JL. Hyperglycemia and glucosuria in preterm infants receiving parenteral glucose: influence of birth weight, gestational age and infusion rate. J Pediatr (Rio J) 1998; 74: 389-396.

8 Garg R, Agthe AG, Donohue PK, Lehmann CU. Hyperglycemia and retinopathy of prematurity in very low birth weight infants. J Perinatol 2003; 23: $186-194$.

9 Ertl T, Gyarmati J, Gaal V, Szabo I. Relationship between hyperglycemia and retinopathy of prematurity in very low birth weight infants. Biol Neonate 2006; 89: $56-59$

10 Capes SE, Hunt D, Malmberg K, Gerstein HC. Stress hyperglycaemia and increased risk of death after myocardial infarction in patients with and without diabetes: a systematic overview. Lancet 2000; 355: 773-778.

11 Umpierrez GE, Isaacs SD, Bazargan N, You X, Thaler LM, Kitabchi AE. Hyperglycemia: an independent marker of in-hospital mortality in patients with undiagnosed diabetes. J Clin Endocrinol Metab 2002; 87: 978-982.

12 Faustino EV, Apkon M. Persistent hyperglycemia in critically ill children. $J$ Pediatr 2005; 146: 30-34.

13 van den Berghe G, Wouters P, Weekers F, Verwaest C, Bruyninckx F, Schetz M et al. Intensive insulin therapy in the critically ill patients. $N$ Engl J Med 2001; 345: 1359-1367.

14 Van den Berghe G, Wilmer A, Hermans G, Meersseman W, Wouters PJ, Milants I et al. Intensive insulin therapy in the medical ICU. $N$ Engl J Med 2006; 354: 449-461.

15 Ellger B, Debaveye Y, Vanhorebeek I, Langouche L, Giulietti A, Van Etten E et al. Survival benefits of intensive insulin therapy in critical illness: impact of maintaining normoglycemia versus glycemia-independent actions of insulin. Diabetes 2006; 55: 1096-1105.

16 Chiarelli F, Spagnoli A, Basciani F, Tumini S, Mezzetti A, Cipollone F et al. Vascular endothelial growth factor (VEGF) in children, adolescents and young adults with Type 1 diabetes mellitus: relation to glycaemic control and microvascular complications. Diabet Med 2000; 17: 50-656.

17 Genuth S. Insights from the diabetes control and complications trial/ epidemiology of diabetes interventions and complications study on the use of intensive glycemic treatment to reduce the risk of complications of type1 diabetes. Endocr Pract 2006; 12(Suppl 1): 34-41. 
18 Poulaki V, Qin W, Joussen AM, Hurlbut P, Wiegand SJ, Rudge J et al. Acute intensive insulin therapy exacerbates diabetic blood-retinal barrier breakdown via hypoxia-inducible factor-1alpha and VEGF. J Clin Invest 2002; 109: $805-815$

19 Meetze W, Bowsher R, Compton J, Moorehead H. Hyperglycemia in extremely low-birth-weight infants. Biol Neonate 1998; 74: 214-221.
20 Hay WW. Early postnatal nutritional requirements of the very preterm infant based on a presentation at the NICHD-AAP workshop on research in neonatology. J Perinatol 2006; 26(Suppl 2): S13-8.

21 Binder ND, Raschko PK, Benda GI, Reynolds JW. Insulin infusion with parenteral nutrition in extremely low birth weight infants with hyperglycemia. J Pediatr 1989; 114: 273-280. 